\title{
Learning of food preferences: mechanisms and implications for obesity \& metabolic diseases
}

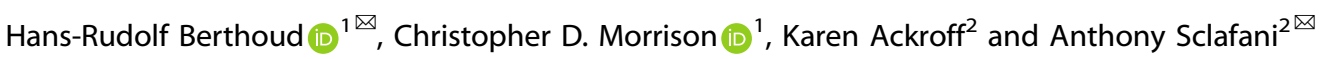 \\ (c) The Author(s) 2021
}

\begin{abstract}
Omnivores, including rodents and humans, compose their diets from a wide variety of potential foods. Beyond the guidance of a few basic orosensory biases such as attraction to sweet and avoidance of bitter, they have limited innate dietary knowledge and must learn to prefer foods based on their flavors and postoral effects. This review focuses on postoral nutrient sensing and signaling as an essential part of the reward system that shapes preferences for the associated flavors of foods. We discuss the extensive array of sensors in the gastrointestinal system and the vagal pathways conveying information about ingested nutrients to the brain. Earlier studies of vagal contributions were limited by nonselective methods that could not easily distinguish the contributions of subsets of vagal afferents. Recent advances in technique have generated substantial new details on sugar- and fat-responsive signaling pathways. We explain methods for conditioning flavor preferences and their use in evaluating gut-brain communication. The SGLT1 intestinal sugar sensor is important in sugar conditioning; the critical sensors for fat are less certain, though GPR40 and 120 fatty acid sensors have been implicated. Ongoing work points to particular vagal pathways to brain reward areas. An implication for obesity treatment is that bariatric surgery may alter vagal function.
\end{abstract}

International Journal of Obesity (2021) 45:2156-2168; https://doi.org/10.1038/s41366-021-00894-3

\section{INTRODUCTION}

The prevalence of obesity and associated metabolic diseases is still increasing globally $[1,2]$, despite increased awareness and intensive research efforts. It is currently assumed that changes in environment and lifestyle are key drivers in this global pandemic [3]. By providing a background of increased availability of energy-dense foods and physical inactivity there is increased pressure on energy balance regulation that leads to increased adiposity in genetically predisposed individuals [4]. Environmental pressures to overeat are particularly strong and are intricately tied to the modern food industry that promotes the consumption of cheap energy-dense but often nutritionally poor foods beginning in childhood by maximizing palatability and using heavy advertisement $[5,6]$. Understanding the physiological mechanisms determining food choice are crucial for the development of behavioral, pharmacological, and even surgical strategies to combat obesity and T2D, and to promote overall healthy eating. Why are we eating what we eat? How does the gut detect ingested nutrients? How does the gut signal nutrient reward to the brain? This review tries to answer at least some of these questions. After a brief description of the many senses and the neurophysiological integrative mechanisms leading to ingestive behavior, we will pay particular attention to gut-brain communication and its role in ingestive behavior and the development of obesity. We will discuss the physiological mechanisms underlying learned nutrient preferences, with special emphasis on sugar and fat preference, for which new mechanisms have recently been proposed.

\section{THE BIOLOGY OF FOOD CHOICE Historical background}

Given the vital importance of ingestive behavior, its neural control mechanisms are robust, redundant, and evolutionarily conserved. In addition to energy from the three macronutrients, an adequate intake of essential nutrients, vitamins, and minerals is important for survival. All these essential food components are typically mixed in natural and processed foods, and adequate intake of each component is an extremely difficult and complex task for the putative control system. While early nutrition physiologists strongly believed in the ability of animals including humans to solve this complex task without much problem [7, 8], subsequent studies and analyses often failed to support this optimistic assumption (e.g. [9]). Twenty years ago, we edited a book entitled "Neural and Metabolic Control of Macronutrient Intake", with a collection of over 30 essays by leading scientists laying out their evidence (or lack thereof) for self-regulation of nutrient intake [10]. Lacking much information on the specifics of neural and metabolic controls at that time, the collection of papers was at least able to answer the basic question of whether there is

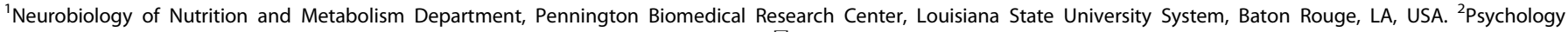
Department, Brooklyn College of the City University of New York, Brooklyn, NY, USA. ${ }^{凶}$ email: berthohr@pbrc.edu; anthonys@brooklyn.cuny.edu 


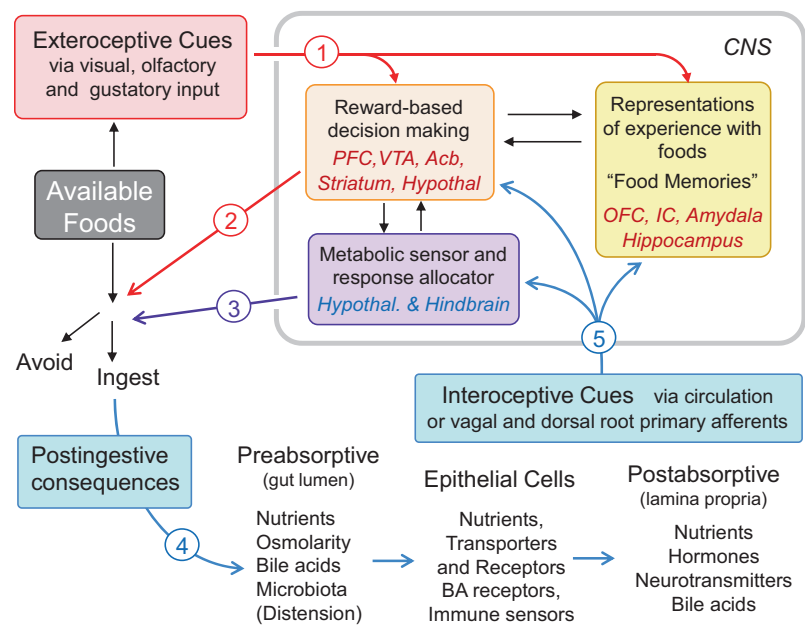

Fig. 1 Schematic diagram showing the main flow of information during the task of choosing food. (1) Before ingestion, available foods with their environmental context are perceived through visual, olfactory, and taste cues that may recall memories from previous encounters. (2) Food items found safe and providing positive nutritional signals are selected/preferred over other available foods and ingested. (3) Selection is thereby modulated by the overall nutritional state monitored by the master metabolic sensor in the basomedial hypothalamus. (4) Once accepted and ingested, the chosen food elicits a large number of temporally contingent signals from interaction with components of the alimentary canal, including enteroendocrine cells and neuropod cells. (5) Select signals in the circulation or via primary afferents are used by the brain to initially sustain ingestion (appetition), and later stop ingestion (satiation). They are also used to update existing memories of the selected food, or form new memories. The three general functional brain areas indicated and the specific brain structures included do not necessarily represent the exact neural pathways and systems and rather serve heuristic models. Abbreviations: Acb nucleus accumbens, BA bile acids, IC insular cortex, OFC orbitofrontal cortex, PFC prefrontal cortex, VTA ventral tegmental area (mesolimbic dopamine system).

evidence for self-regulation of different nutrients. The general conclusion was that there is a hierarchy in nutrient self-regulation, with good evidence that intake of salt and protein (essential amino acids in particular) are actively defended (hard regulation), but weak evidence for carbohydrates (soft regulation), and little to no evidence for fat (no regulation) [11].

Amino acids cannot be synthesized by the body and are physiologically important, but in contrast, most carbohydrates and lipids can be synthesized internally. Specific putative deficit signals for low-protein (Fibroblast Growth Factor-21, FGF21) and low-salt (aldosterone/angiotensin II), but not for low-carbohydrate or lowfat availability have been identified. A deficit in energy as signaled by low leptin appears to drive intake of all three energy-providing macronutrients equally [12]. However, the absence of specific feedback mechanisms for the intake of carbohydrates and fat does not necessarily mean that there are no mechanisms to detect these nutrients in ingested food and inform other regulatory functions.

\section{Evidence for self-regulation of protein, carbohydrates, and fat intake}

When conducting studies assessing selection between the three macronutrients (protein, carbohydrate, and fat), a common but problematic approach is to provide animals with a single, purified representative of each macronutrient, such as providing casein, sugar, and lard in independent jars within the cage. The weakness of this approach is the potential for the specific sensory properties of the food, such as the powdery dry taste of casein and the greasy taste of lard, to drive selection instead of the nutrient composition itself. To address this approach, multiple representations of the macronutrient should be tested, or more ideally the experiment should include a variety of mixed diets varying in their macronutrient percentage but otherwise nutritionally complete (vitamins and minerals), as in the geometric model of macronutrient selection [13].

Using the geometric model, nutritional state-dependent selfregulation of protein intake has been demonstrated in rats, cats, and insects (for a recent review see: [13]). However, besides liverderived FGF21 being a driver of protein intake (see Hill et al. for a recent review [14]), details of the neurohormonal signaling mechanisms and pathways underlying the self-regulation of protein intake remain ill-defined despite intensive research efforts (for reviews see: [15-17]).

Carbohydrate and fat intake have recently received much attention from obesity, diabetes, and metabolic disease standpoints. In particular, dietary sugar intake is thought to be a prominent risk factor for these chronic diseases [18, 19]. Behavioral evidence for self-regulation of carbohydrate intake is weak at best [20], and almost absent for fat intake.

\section{Potential mechanisms for macronutrient choice}

The basic task of finding a particular nutrient in complex food can be nothing less than the proverbial task of finding a needle in a haystack. Although sight, smell, and taste can contribute important information for finding the needle, they are not necessary. Tasteless mice, knockout mice missing critical taste signaling elements, on normal chow or palatable diets still eat and gain weight, although in some but not all cases significantly less than their wildtype littermates [21-23]. Similarly, it might be an interesting experience having dinner in one of these new restaurants with complete darkness, but the feeling of fullness and satisfaction might be the same even if we eat a little less [24]. In contrast, postoral (post ingestive) detection mechanisms, particularly detection at the level of the intestinal epithelium, where absorption takes place, are crucially important for providing the unconditioned stimulus signaling the arrival of ingested nutrients and leading to fullness, reward, and satisfaction (Fig. 1). As demonstrated in the sham-feeding model with a gastric drainage fistula, a hungry rat will not become satiated in spite of continued ingestion of food for hours. Only placing small amounts of food into the small intestine or systemic administration of cholecystokinin in sham-feeding rats stops food intake and elicits behavioral signs of satiation and satisfaction [25].

Importantly, oral sensory signals such as taste and smell can act as conditioned stimuli determining intake of particular foods through learning. If these signals have reliably predicted the arrival of absorbable and beneficial nutrients (the unconditioned stimulus, US), the food is readily ingested $[26,27]$. If the food does not reliably predict the US, then its acceptability will not increase and it may be rejected and the search for a more beneficial food continues (Fig. 1). The reinforcing properties of the US are influenced by the nutritional state, although learning can occur even in food-satiated animals [27]. As shown in Fig. 1, this process is thought to involve a number of pathways and brain areas. Besides the interoceptive and exteroceptive sensory modalities and pathways, areas in the cortex, amygdala, and hippocampus can generate and store representations of experience with specific foods. Together with signals from the hypothalamus and hindbrain reflecting overall nutritional state and from components of the limbic system representing the reward value of specific foods, these "food memories" are then used to make ingestive decisions. However, these central integrative steps subserving food choice are not well understood and are not further considered in this review.

Before looking at experimental paradigms of nutrientconditioned preferences and recent advances in understanding 
the mechanisms underlying preference learning for sugar and other macronutrients, we will have a closer look at the organization of gut-brain communication as it pertains to nutritional homeostasis.

\section{ORGANIZATION OF GUT-BRAIN COMMUNICATION SUBSERVING NUTRITIONAL HOMEOSTASIS \\ Mechanosensors}

The postoral consequences of foods include interactions with mechanical, chemical, and osmotic sensors (Fig. 2). Vagal stretch receptors (intramuscular arrays, IMAs) are mainly found in the stomach, while vagal tension sensors (intraganglionic laminar endings, IGLEs) are distributed throughout the gastrointestinal tract $[28,29]$. Importantly, selective opto- or chemogenetic stimulation of vagal afferent neurons with IGLEs innervating both the stomach and small intestine inhibits 1-h food intake in fooddeprived mice by $50 \%$ or more [29], suggesting that gastric and intestinal distension significantly contribute to the satiation process. However, because the mechano-sensory signal is blind to the nutritive value of the load, it cannot serve as the US for flavor learning.

\section{Chemosensors for macronutrients}

After emptying from the stomach, nutrients interact with pancreatic juices, bile acids, and microbiota in the small intestinal lumen before traversing the gut epithelial barrier. The epithelial layer consists of several types of cells, including enterocytes, enteroendocrine cells (ECs), and mucin-secreting goblet cells that differentiate from stem cells located in the crypts and are constantly renewed every 3-5 days [30]. ECs are specialized epithelial cells making up less than $1 \%$ of the epithelium that function as sensory sentinels, by responding to luminal stimuli and secreting peptide hormones and neurotransmitters [31].

Dietary carbohydrates, proteins, and fats are progressively digested by mastication and salivary enzymes in the mouth, trituration, and acidification in the stomach, and finally by pancreatic juices, bile acids, and microbiota in the lumen of the small intestine, before they are ready for absorption. Glucose and galactose then enter the brush border membrane of enterocytes using almost exclusively the sodium-glucose transporter-1 (SGLT1), while fructose uses the glucose transporter-5 (GLUT5) (for a recent review see [32]). SGLT1 is pivotal for intestinal glucose absorption, as SGLT knockout mice die within two days after weaning when they receive standard starch-based diets [33]. The glucose transporter-2 (GLUT2) is located exclusively at the basolateral membrane at low luminal glucose concentrations, and at both the brush border and basolateral membranes at high luminal glucose concentrations [32]. In addition, nutritive sugars and nonnutritive sweeteners activate the G-protein-coupled sweet taste receptor T1R2/3 expressed in the apical membrane of some ECs [34].

Dietary protein, after hydrolysis by gastric and pancreatic peptidases, is internalized into enterocytes via peptide transporter-1 (PEPT1) linked to the $\mathrm{Na}^{+} / \mathrm{H}^{+}$exchanger, the calcium-sensing receptor (CaSR), and the recently deorphanized G protein-coupled receptor GPRC6A [34, 35]. Small peptides and individual amino acids are then transported by peptide and amino acid transporters across the basolateral membrane into the lamina propria. In addition, certain amino acids such as glutamate activate the G-protein-coupled umami taste receptor T1R1/3 [34].

Dietary fats, after being emulsified and processed into mixed micelles through the action of lipases and bile acids, are transported into enterocytes by (1) the fatty acid transporter-4 (FATP4), (2) fatty acid translocase (CD36) with the help of membrane-bound $\left(F A B P_{m}\right)$ and cytoplasmic $\left(F A B P_{c}\right)$ fatty acidbinding proteins, and (3) the Nieman-Pick $\mathrm{C} 1$ like 1 protein (NPC1L1) [36]. Long- and medium-chain containing triglycerides and cholesterol are then assembled into chylomicrons and exported through the basolateral membrane where they are transported by the lymphatic system to the general circulation, while short-chain fatty acids (SCFAs) are freely diffusing through enterocytes to reach the bloodstream through the hepatic-portal vein [36].

Individual enteroendocrine cells can produce different combinations and quantities of peptide hormones and are sprinkled in different proportions over the length of the gastrointestinal tract. CCK and GIP cells are enriched in the upper small intestine, GLP-1 and PYY in the lower small intestine and colon, and ghrelin in the stomach [37]. Importantly, specific intracellular signaling mechanisms involving ion channels, membrane depolarization, and intracellular calcium, link nutrient absorption to hormone release, whereby each macronutrient elicits its specific fingerprint of gut hormones released [37] (Fig. 2). Given the scarcity of enteroendocrine cells among the many absorptive enterocytes, paracrine crosstalk between common enterocytes and enteroendocrine cells as well as between enteroendocrine cells is important [38]. Thus, enteroendocrine cells are sentinels transducing bulk macronutrient absorption into the information available for the gut itself and for all other organs (Fig. 2).

\section{Neural signaling pathways to the brain}

The gastrointestinal tract is heavily innervated by both vagal and dorsal root afferents. Dorsal root afferents are generally thought to mediate pain rather than normal physiological signals [39], but a role in nutrient homeostasis is not excluded. Spinal primary afferent neurons with cell bodies in dorsal root ganglia innervate the entire gastrointestinal tract and associated glands, and their total number compares well with the number of vagal subdiaphragmatic afferents [40]. Single spinal visceral afferents distribute over many segments [41], thus contributing to homeostatic regulation of a wide range of organs. Furthermore, they gain easy access to most brain areas through the spinosolitary, spino-parabrachial, spino-hypothalamic, and other tracts and therefore have the potential to affect the same brain areas that are affected by vagal afferents.

Here we focus on vagal afferents, for which there is rich literature describing their role in nutrient homeostasis and ingestive behavior. We have already introduced vagal afferent innervation of the external muscle layers of stomach and intestines by IMA and IGLE mechanosensors and their ability to modulate food intake. However, vagal afferents innervating the mucosa throughout the gastrointestinal tract are in a much better position to sense the chemical milieu in the lamina propria, as their terminals are in close contact with freshly absorbed nutrients $[42,43]$ and ECs with their secretory products $[44,45]$. There is plenty of older literature, from before the discovery of most gut hormones, suggesting that vagal afferents are sensitive to a variety of nutrients, including glucose, amino acids, and fatty acids [46-50]. Later, expression of many gut hormone receptors by vagal afferents innervating the gut, and at least some evidence for their role in ingestive behavior was reported. After the early discovery of CCK, the potential role of CCK and its CCKA-receptor on vagal afferents in the process of satiation was of most interest $[42,43,51-53]$. More recently, interest shifted to the role of GLP-1 released from intestinal L-cells and the GLP-1 receptor expressed by vagal afferents in satiation [54-56].

However, sub-optimal methodology in many of these earlier studies often prevented clear conclusions to be drawn. Perhaps the major problem was an inability to manipulate and visualize functionally specific populations of vagal afferents. Vagotomies were typically non-specific, not only regarding afferent subtype and specific tissue/organ innervated, but also regarding afferent vs. efferent. Visualization of receptors was typically limited to immunohistochemistry of vagal afferent neuronal cell bodies in the nodose ganglia, without knowing their specific innervation targets. This is exemplified by experiments in rodents surgically 


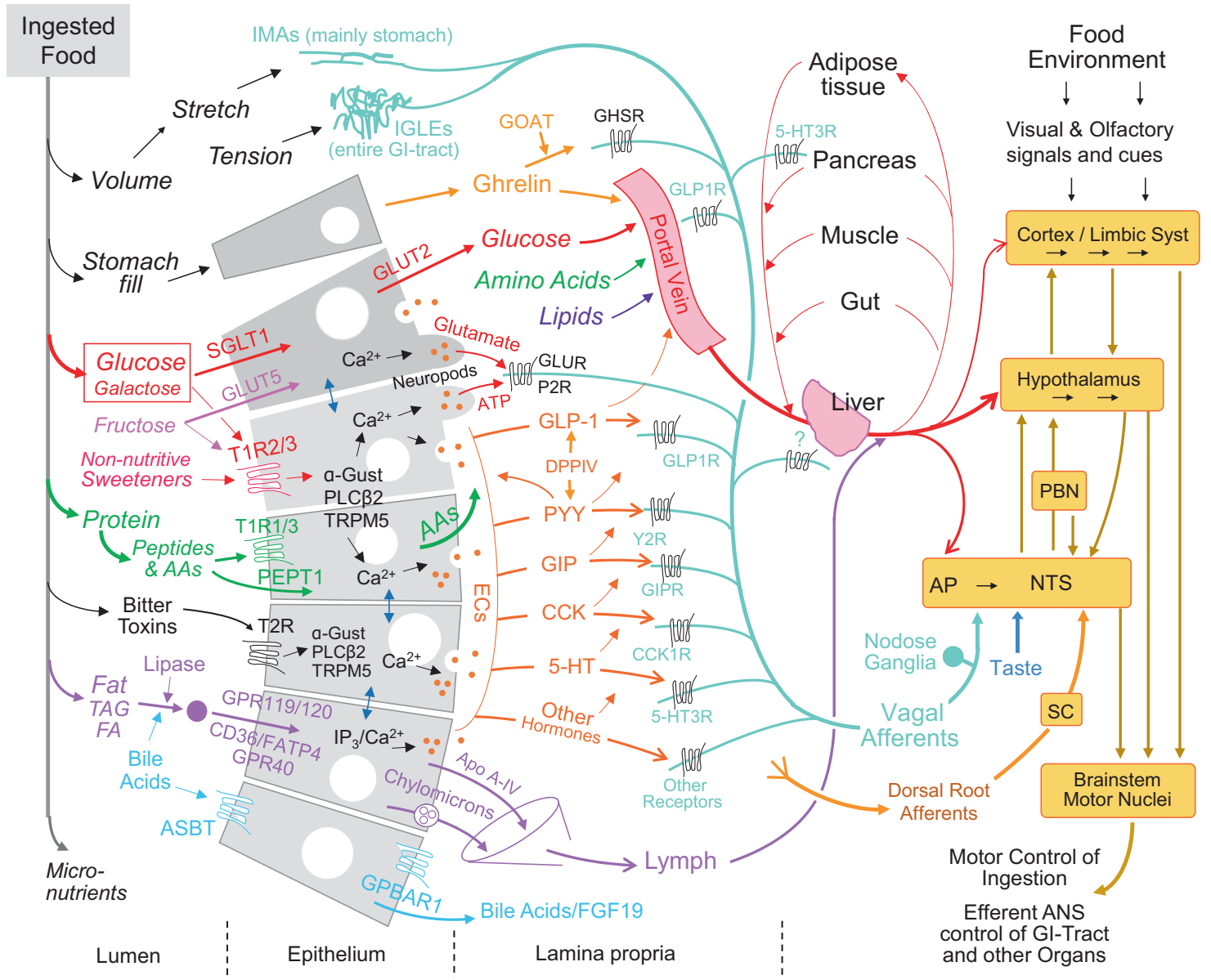

Fig. 2 Nutrient signaling in the gastrointestinal tract and its communication pathways to other organs and the brain. The volume and osmotic effects of ingested foods interact with the muscular wall of the alimentary canal and can activate vagal stretch (Intramuscular arrays, IMAs) and tension receptors (Intraganglionic laminar endings, IGLEs). Entry of carbohydrates, proteins, and fats into enterocytes is facilitated by specific transporters localized to the brush border apical membrane. Sugars, amino acids, and lipids are then diffusing into the mucosal lamina propria. Enteroendocrine cells (ECs) represent about $1 \%$ of all intestinal epithelial cells that can synthesize and release one or more gut hormones. Once transported into these ECs, carbohydrates, amino acids, and lipids differentially engage intracellular signaling pathways eventually leading to membrane depolarization, increased calcium concentrations, and the release of hormone-containing vesicles into the lamina propria. Some ECs with specialized extensions into the lamina propria (neuropod cells) can release the neurotransmitter glutamate onto vagal afferent nerve terminals bearing glutamate receptors. In addition, sugars and nonnutritive sweeteners are detected by the sweet receptor T1R2/3 and can trigger the synaptic release of ATP in neuropod cells acting on P2R on vagal afferent terminals. Nutrients and hormones in the lamina propria then have access to the bloodstream, mucosal vagal nerve endings, and the lymph system. Nutrients and hormones taken up into the bloodstream (either directly or after transport through the lymphatic system) can interact with vagal sensors in the portal vein or liver and eventually with sensors in all other organs and specific areas of the brain. Crosstalk between different ECs and between ECs and common enterocytes, as well as crosstalk between ECs and the enteric nervous system (ENS) are not shown for simplicity. Also note that innervation of the gut, portal hepatic vein, and liver by dorsal root afferents (DRG), which can also mediate signals to the brain are not shown. Abbreviations: Molecular transduction mechanisms: GLUT2 glucose transporter-2, GLUT5 glucose transporter-5, SGLT1 sodiumglucose transporter-1, T1R2/3 sweet taste receptor, T1R1/3 umami taste receptor, T2R bitter taste receptor, PEPT1 peptide transporter-1, $\alpha$-Gust $\alpha$-gustducin, PLC phospholipase C, TRPM5 transient receptor potential cation channel subfamily M member 5 , IP 3 inositol triphosphate, ASBT apical sodium-dependent bile acid transporter, GPBAR1 G protein-coupled bile acid receptor 1. Hormones and enzymes: GLP-1 Glucagon-like peptide-1, PYY peptide YY, GIP Gastric inhibitory peptide, CCK cholecystokinin, 5-HT serotonin, GOAT ghrelin-O-acetyl transferase, DPPIV dipeptidyl peptidase-4, FGF19 fibroblast growth factor 19/15, Apo A-IV apolipoprotein-4. Receptors on vagal afferents: GLP1R GLP-1 receptor, Y2R PYY-2 receptor, GIPR gastric inhibitory peptide receptor, CCK1R cholecystokinin-1 receptor, 5-HT3R serotonin-3 receptor, GHSR growth hormone secretagogue receptor, GLUR glutamate receptor, P2R purinoreceptor. Brain: PBN parabrachial nucleus, AP area postrema, NTS nucleus tractus solitarius, SC spinal cord.

interrupting the common hepatic branch dividing from the left subdiaphragmatic vagal trunk. The rat common hepatic vagal branch contains both afferents and efferents (and even some nonvagal nerve fibers [57], and projects primarily to the proximal duodenum, pylorus, and pancreas via the gastroduodenal artery. It also innervates the portal hepatic vein, and only a small fraction actually innervates the liver itself along the hepatic artery [58]. Therefore, this complicates the interpretation of the functional effects of common hepatic branch vagotomy, particularly when looking at longer-term effects.
Specific labeling and manipulation of sub-populations of vagal afferents by genetics-based tools is the most significant advance for understanding their role in nutritional homeostasis [29, 59-65]. Two studies, in particular, reported molecular maps of targetspecific vagal sensory neurons using single-cell RNA sequencing $[29,64]$. This allowed the generation of separate Cre-mouse lines and identification of their unique morphologies and innervation patterns in the gastrointestinal tract [29], confirming the presence of the three distinct sensory terminal architectures, namely IMAs, IGLEs, and mucosal endings, previously described after 
nonselective anterograde tracing with Dil in the rat (as summarized in [28]). In addition, however, the genetic approach allows selective manipulation (acute and chronic stimulation and inhibition) of such specific populations of vagal sensory neurons $[29,61]$.

Besides releasing gut hormones, some specialized enteroendocrine cells (neuropod cells) penetrate the basolateral membrane and can release neurotransmitters directly on vagal afferent nerve terminals that are synaptically opposed [66]. More recently, these neuropod cells have been demonstrated to mediate the SGLT1dependent glucose-signal rapidly to vagal afferents through glutamatergic signaling [67-69]. Such direct synaptic connections allow for very rapid signaling to the brain and together with the viscerotopic organization of vagal afferents have the potential to inform the brain what is absorbed at a given location on a secondby-second basis.

\section{Humoral signaling}

Given that the focus of this review is on nutrient-conditioned preferences and that much recent work implicates neural pathways, our discussion of humoral mediation is limited to a few essential points. For more comprehensive reviews on humoral gut-brain signaling relevant to obesity and metabolic disease see e.g., [70]. Besides signaling through primary afferents, nutrients and hormones can also signal to the brain via blood circulation. Once released into the lamina propria they are taken up by mucosal capillaries to reach the hepatic-portal vein and eventually all other organs including the brain. Some gut hormones such as GLP-1, PYY, and ghrelin, are subject to modifications by peptidases and other enzymes, which can greatly reduce or enhance their binding to specific receptors. Concentrations of specific nutrients and hormones are significantly higher in hepatic-portal blood compared to general arterial blood concentrations. Chylomicrons and hormones such as ApoAIV and GLP-1 are also transported by the lymph system, which bypasses the hepatic-portal vein and liver, to enter the general circulation via the subclavian vein [36].

In the brain, nutrients and hormones can more or less affect neurons and glia depending on the permeability of the blood-brain barrier. Areas without or with a weak blood-brain barrier such as the area postrema in the hindbrain, and the median eminence in the basomedial hypothalamus are most strongly affected, but hormones and nutrients can affect most other brain areas if adequate transport systems exist. Hormones and other humoral factors such as leptin, insulin, and FGF21 secreted by these other organs are clearly important for overall nutritional homeostasis, by interacting with humoral and neural signals from the gut at many levels.

In contrast to the fast, high fidelity neural connections, humoral signaling is slower and generally conveys little viscerotopic information. On the other hand, humoral signals have the potential to act in a more sustained and integrative fashion.

\section{EXPERIMENTAL PARADIGMS FOR FOOD PREFERENCE \\ LEARNING}

A broad question, which has been answered in increasing detail in recent years, concerns which of the gut sensing and signaling mechanisms described in the previous sections are crucial for the development of food preferences. This section introduces the techniques used to train and measure preferences in laboratory rodents.

Animals learn to associate the flavor of food, that is, its taste, smell, texture, and other oral chemesthetic cues with the food's postoral (post ingestive) consequences [26, 27, 85]. This learning can occur with short- or long-term sessions (30 min-24h) and under food sated or restricted states. In the laboratory, the "food" is often a flavored nonnutritive solution (or gel) with postoral consequences manipulated by the experimenter. The outcome of this learning is typically expressed in subsequent encounters with the food in choice (e.g., two-bottle test) or no-choice (one-bottle test) situations. If the food contains toxins or poorly digested nutrients (e.g., lactose) that produced gastrointestinal distress, animals rapidly learn to avoid its flavor. Conditioned flavor aversions are well documented as reviewed elsewhere $[27,72,73]$. Of interest here are flavors that are associated with positive reinforcing consequences [27]. In this case, animals may learn to prefer the flavored solution (conditioned flavor preference) as evidenced by their preferential intake in choice tests and may also increase their absolute intake of the flavored solution (conditioned flavor acceptance) (Fig. 3). Total intakes may not increase with concentrated nutrient sources which limit intake although initial rates of ingestion and/or meal sizes may be enhanced [74]. This process, in which the ingestion/absorption of nutrients promotes positive associations that increase preference is termed appetition, and thus postoral cues that increase preference and/or acceptance are referred to as 'appetition' cues to distinguish them from 'satiation' cues that decrease intake [75].

A simple procedure to study flavor-nutrient learning is to train animals on alternate days to consume a novel flavor (the conditioned stimulus, CS+, e.g., grape) mixed in a nutrient solution (the unconditioned stimulus, US, e.g., sucrose) and a different flavor (the CS-, e.g., cherry) mixed in water and then assess the conditioned preference/acceptance in subsequent choice tests with the $\mathrm{CS}+$ and $\mathrm{CS}$ - flavors presented in water. A potential problem with this paradigm, however, is that the animal may acquire a CS+ flavor preference based on its association with the palatable flavor of the nutrient (e.g., sweet taste) rather than (or in addition to) the nutrient's postoral actions. Flavor-flavor learning is demonstrated by the learned preference for a CS+ flavor mixed into a nonnutritive sweet solution (e.g., saccharin, sucralose) [27]. To eliminate this flavor-flavor association, animals can be trained with the CS+ flavor added to a sugar solution and the CS- flavor added to a nonnutritive solution matched in palatability to the sugar $[76,77]$. Any resulting $\mathrm{CS}+$ preference can thereby be attributed to the postoral actions of the sugar rather than its sweet taste. In one variation of this procedure, animals are trained to consume sugar and nonnutritive sweetener solutions (without added flavors) with the nonnutritive solution being matched or even more palatable than the sugar solution [65, 78] (Fig. 3A). If animals develop preferences for the sugar (which is both the CS+ and US) over the nonnutritive sweetener (CS-) after training, this preference is indicative of postoral sugar conditioning. This type of learning is possible because even if the sugars and nonnutritive sweeteners are "isosweet", they differ in other flavor characteristics that allow animals to discriminate their flavors. Thus, postoral sugar conditioning can enhance the innately attractive sweet taste of sugar itself as well as for any associated flavors (e.g., the flavor of a sugar-rich mango).

An alternative procedure to investigate flavor-nutrient learning is to train animals to drink differently flavored solutions of similar palatability (e.g., both unsweetened or saccharin-sweetened fruit flavors) but with the CS+ flavor paired with intragastric (IG) nutrient infusions and the CS- paired with IG water infusions $[26$, 27] (Fig. 3B). Flavor preferences can be conditioned by IG infusions of complete liquid diets or individual macronutrients (carbohydrate, fat, protein). This conditioning method is very potent in that it (a) can convert innate aversions to bitter or sour tastes to strong preference and (b) produces long-lasting preferences that are resistant to forgetting or extinction [27, 85]. Another method for evaluating the reinforcing actions of nutrients involves pairing a place (e.g., distinctive chamber) or sipper tube position with the consumption of a nutritive substance (e.g., sucrose solution) $[79,80]$. Unlike the case of conditioned flavor preferences, the resistance to extinction of conditioned place/ position preferences over several trials has not been established. 

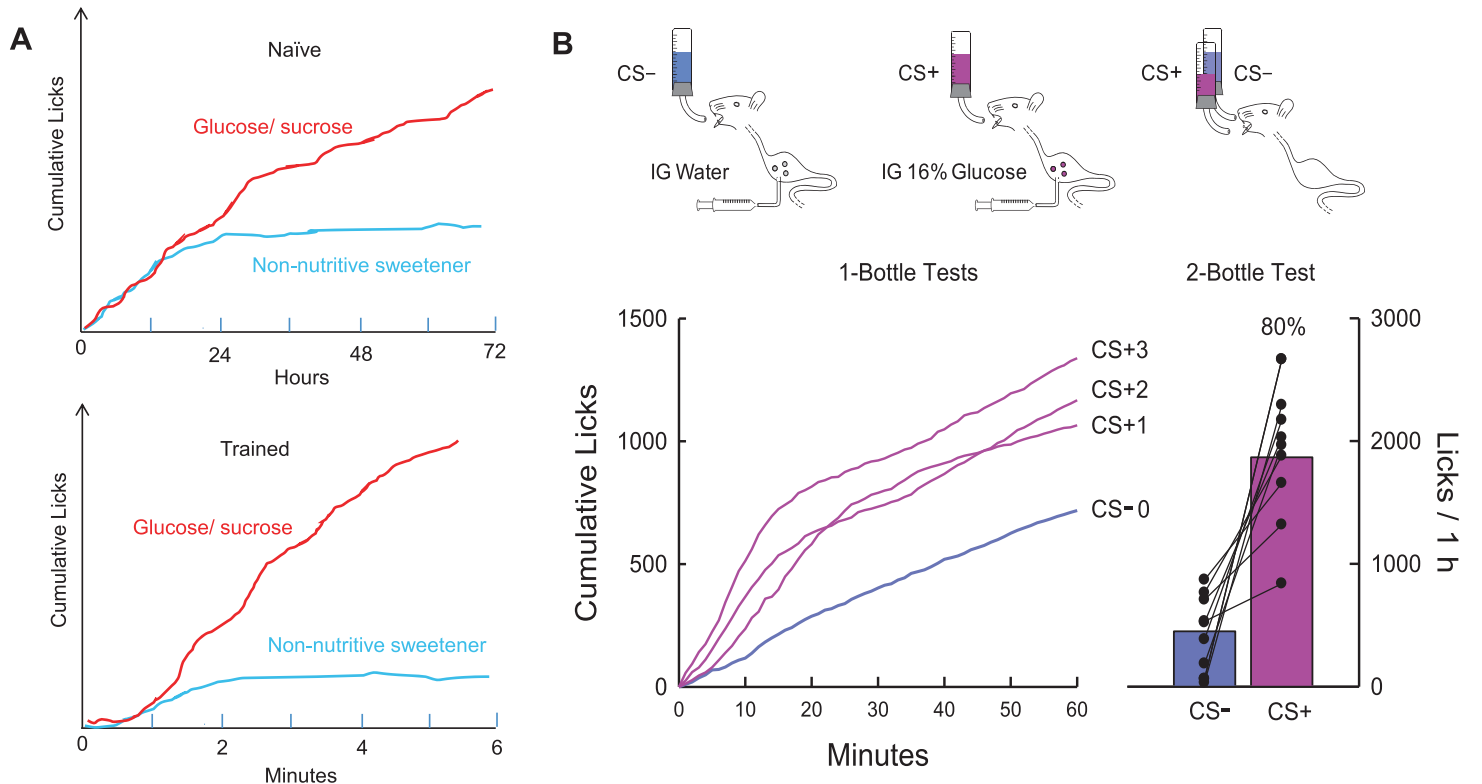

Fig. 3 Nutrient-conditioned flavor preferences. A Naïve mice given two-bottle access to "isosweet" nutritive sugars (glucose or sucrose) and nonnutritive sweeteners (sucralose, AceK) take $24 \mathrm{~h}$ or more to develop a preference for the sugar. Once trained, a sugar preference is expressed in less than 2 min $[65,68,136]$. B Naïve mice given one-bottle access (1 h/day) to a CS+ flavored saccharin solution paired with IG $16 \%$ glucose infusion increase their licking response within $10 \mathrm{~min}$ in the first test session (CS+1) compared to prior sessions with a CS- flavor paired with IG water (CS-0). In subsequent one-bottle CS+ sessions licking is increased from the very first min. In two-bottle tests all mice licked more for the CS+ than CS-; $80 \%$ CS + preference. Because mice were not infused in 2-bottle tests they licked much more than in onebottle tests [94].

More recently, postoral nutrient reinforcement has been evaluated in mice by using self-administration procedures in which an operant response (licking unflavored water or a dry sipper tube, lever pressing) is reinforced by IG nutrient infusions (e.g., sugar, fat) [71, 81-83]. As discussed below, a new development in the study of food preference learning is the use of opto/chemogenetic approaches to target-specific neurons activated by postoral nutrients to condition flavor preferences or block the expression of previously learned preferences [65, 68, 84].

\section{MECHANISMS FOR SUGAR-CONDITIONED PREFERENCES}

The nutrient conditioning actions of carbohydrates are extensively documented using various sugars, maltodextrins, or starches [27]. Rats and mice trained in alternate daily sessions ( $30 \mathrm{~min}-24 \mathrm{~h}$ ) to drink a CS + flavored solution paired with concurrent IG infusions of $8-32 \%$ glucose-based carbohydrates (glucose, sucrose, maltose, maltodextrin) and a CS- flavor paired with IG water infusions subsequently displayed a significant (70-90\%) preference for the CS+ over the CS- flavor in two-choice tests [27, 85] (Fig. 3). Carbohydrate conditioned preferences have been considered to be a form of "flavor-calorie" learning, but isocaloric carbohydrates can differ substantially in their effectiveness to condition flavor preferences. In particular, in rats and some mouse strains (FVB/N) IG fructose infusions condition much weaker flavor preferences than do isocaloric glucose infusions and in some mouse strains (e.g., C57BL/6, B6) IG fructose is completely ineffective [74, 86-88].

\section{Transduction site of postoral sugar signal}

Information on the site(s) of action for postoral carbohydrate conditioning is provided by results obtained with different postoral infusions. In rats, (a) IG glucose infusions conditioned flavor preferences only when the sugar was allowed to empty into the intestinal tract [89] (b) glucose infused in the duodenum or jejunum, but not the ileum, conditioned flavor preferences [90]; and (c) glucose infusions into the hepatic-portal vein failed to condition preferences for a nonnutritive CS+ solution [90]. These results implicate the upper intestinal tract as a critical site of action for glucose sensing [85] (Fig. 4). Hepatic-portal glucose infusions conditioned a preference for a CS+ flavored chow that itself provided intestinal nutrient stimulation [91], suggesting that portal glucose is an effective conditioning stimulus when combined with preabsorptive nutrient stimulation. Consistent with this interpretation, portal glucose infusions conditioned preferences for flavored glucose but not for flavored saccharin solutions [90]. Hepatic-portal glucose infusions, however, conditioned a sipper tube side preference and increased dopamine release in the nucleus accumbens which is critical for preference conditioning in rats [92]. Thus, postabsorptive glucose alone supports at least some forms of preference conditioning.

Sweet taste signaling proteins (T1R2, T1R3, gustducin, TRPM5) are expressed in intestinal cells which suggests that intestinal "sweet" sensing could mediate postoral sugar conditioning (Fig. 2). However, this is not supported by the findings that IG infusions of sweet receptor ligands fructose and sucralose do not support flavor conditioning in B6 mice [93, 94]. Furthermore, IG sugar infusions condition strong flavor preferences in knockout (KO) mice lacking T1R3, gustducin, or TRPM5 [85]. Rather than intestinal sweet receptors, glucose-specific sensors/ transporters (SGLT1, SGLT3, and GLUT2) are implicated in postoral sugar conditioning. In B6 mice, IG infusions of a-methyl-D-glucopyranoside (MDG), a non-metabolizable glucose analog that binds to SGLT1 and SGLT3, conditioned a CS+ flavor preference that was blocked by coinfusions of the SGLT1/3 inhibitor phloridzin [94]. IG glucose conditioning was blocked when the infusion included both SGLT1/3 and GLUT2 inhibitors, implicating GLUT2 in glucose conditioning. However, the genetic deletion of SGLT1 was sufficient to block IG conditioning by MDG and glucose [95]. Note that glucose conditions stronger preferences than MDG, which may be due to the ability of postabsorptive glucose but not MDG to promote striatal dopamine release [94, 96]. In addition, the accumulation of the non-metabolizable MDG in the body may generate inhibitory signals that suppress conditioning. Nevertheless, the differential conditioning actions of glucose, fructose 


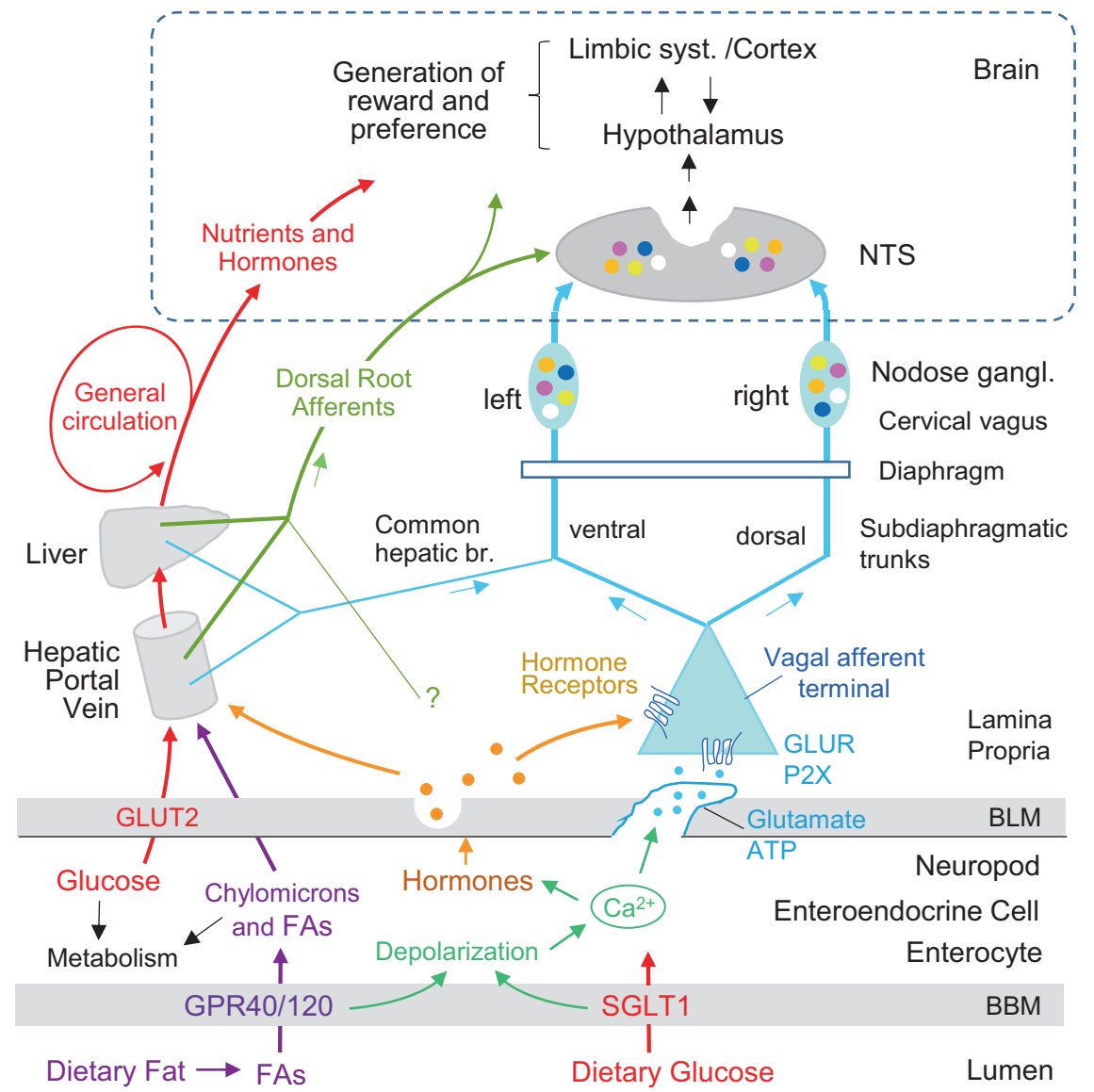

Fig. 4 Proposed gut-brain pathways mediating postoral sugar and fat appetition in mice. (1) SGLT1-mediated glucose transport across the brush border membrane leads to enterocyte depolarization and the release of glutamate from neuropod cells reaching into the lamina propria. The synaptically released glutamate excites glutamate receptors located on sensory nerve terminals originating from unknown vagal afferent neuron populations in both the left and right nodose ganglia and projecting through both left and right cervical vagus [68]. (2) Glucose activates via SGLT1 a selective population of vagal afferent neurons and in turn a selective population of proenkephalin-expressing neurons in the left and right NTS [65]. (3) Glucose metabolism can influence brain reward circuitries by an unknown metabolic sensor and pathway [96]. (4) After absorption and reaching the hepatic-portal vein and liver, glucose activates the mesolimbic dopamine system by acting in an unknown fashion on sensory terminals of vagal afferent fibers passing through the common hepatic branch associated with the left cervical vagus [83]. (Note that these authors speculate that the postoral sucrose may act on neuropod cells or hepatic-portal sensors, admit that there must be pathways in addition to the hepatic vagus; and their outcome behavior is operant sugar seeking) (5) The presence of intestinal glucose is signaled in an SGLT1-dependent fashion via dorsal root afferent neurons passing through the celiac ganglia to inhibit hypothalamic AgRP neurons [103]. (Note that there was no preference testing in this study). Inhibiting AgRP neurons conditions flavor preferences [137]. (6) Fatty acids (FA) derived from dietary fat acting in part on intestinal GPR40 and GPR120 sensors signal brain reward circuits via undefined pathways to condition CS + flavor preferences and promote fat-seeking behavior [112]. (7) Dietary fat acting on unspecified intestinal sensors activate brain reward systems via CCK-sensitive vagal afferent fibers passing through the right nodose ganglion to condition relative preferences for dilute or concentrated fat emulsions and promote operant fat-seeking behavior [84]. (8) Dietary fat acting on unspecified intestinal sensors via vagal afferent neurons to inhibit hypothalamic AgRP neurons [103]. Note that studies in rats indicate that the upper small intestine is partially innervated by vagal fibers traveling in all the anterior and posterior celiac, the anterior and posterior gastric, as well as the gastroduodenal branch dividing from the common hepatic branch [28].

and non-metabolizable MDG are remarkable and indicate that "the signaling system recognizes the sugar molecule itself rather than its caloric content or metabolic products" [65, 94].

\section{Gut-brain pathway for unconditioned sugar signal}

The gut-brain pathway(s) that mediate postoral glucose preference conditioning is not fully understood (Fig. 4). Several studies reported that surgical transection of the subdiaphragmatic vagal trunks (SDV) or subdiaphragmatic deafferentation (SDA) did not prevent glucose-conditioned flavor preferences [97-100]. However, other recent findings implicate a central role for vagal afferents. In particular, intestinal infusions of glucose, sucrose, and MDG, but not fructose were found to act on intestinal neuropod cells and rapidly stimulate vagal afferents via glutamatergic synaptic connections [67,68] (Fig. 4). In addition, optogenetically silencing the neuropod or pharmacologically inhibiting the glutamatergic vagal synapse blocked the expression of a learned preference for sucrose over sucralose [68]. Tan et al. [65] further reported that intestinal infusions of glucose and MDG but not the nonnutritive sweetener acesulfame $\mathrm{K}$ (AceK) activated a bilateral subset of proenkephalin-expressing neurons in the caudal nucleus of the solitary tract (cNTS). The cNTS response was blocked by acute bilateral surgical cervical vagotomy. In 48-h, two-bottle choice tests, B6 mice initially consumed similar amounts of $600 \mathrm{mM}$ glucose and $30 \mathrm{mM}$ AceK solutions but developed a strong glucose preference by the end of the test (Fig. 3). Similar preference changes were observed with MDG vs. AceK but not with fructose vs. AceK, consistent with differential flavor conditioning actions of IG glucose, MDG, and fructose [94]. Evidence that the intestinal-vagal-cNTS circuit activated by 
intestinal glucose and MDG is responsible for the preference conditioning effects of these sugars is indicated by the findings that (a) selective silencing of neurochemically-defined vagal sensory neurons in the nodose ganglia blocked the development of a preference for glucose over AceK and (b) selective silencing of the proenkephalin-expressing cNTS neurons activated by intestinal glucose also blocked development of a preference for glucose [65]. Furthermore, silencing cNTS neurons prevented the overconsumption of glucose, relative to AceK, driven by the sugar's postoral actions.

While the above findings provide compelling evidence that the intestinal-vagal-cNTS circuit mediates the glucose preference conditioning, they do not account for the failure of surgical SDV or SDA procedures to block glucose-conditioned preferences [97-99]. However, it should not be surprising that these very nonselective vagotomies led to misleading outcomes, particularly in chronic situations. Because these crude vagotomies eliminate a great number of vagal fibers with different functionalities, they likely lead to adaptive changes in the bidirectional signaling between the gut and the brain over time. In addition, they may spare critical afferent vagal fibers that are deactivated by optogenetic or neurochemical silencing of neuropod cell signaling or nodose afferents [101]. Alternatively, there may be afferent fiber regeneration after surgical SDV or SDA vagotomy but not after neurochemical nodose vagotomy. Given the finding that acute surgical cervical vagotomy blocked intestinal glucose activation of cNTS neurons [65], it would be most informative to determine if intestinal glucose activates CNTS neurons in animals with acute or chronic SDV or SDA surgery.

Another consideration is the sufficiency of sugar-induced activation of vagal afferents to condition flavor preferences. The differential vagal activation effects of glucose, MDG and fructose [65] are consistent with the differential flavor conditioning effects observed with IG infusions of these sugars [85, 86, 94]. However, intestinal infusions of galactose and non-metabolizable 3-Omethyl-d-glucose (OMG) were similar to glucose and MDG in stimulating vagal nerve activity [65] but IG galactose and OMG were much less effective than glucose and MDG in conditioning CS+ flavor preferences [87, 94]. Because glucose and MDG, unlike galactose and OMG, are ligands for the glucose sensor SGLT3 as well as SGLT1, perhaps both SGLT sensors mediate preference conditioning, although SGLT3 involvement remains uncertain [95]. Alternatively, galactose and OMG may have postabsorptive inhibitory actions that interfere with flavor conditioning [95]. Whatever the reason, the similar vagal activation patterns observed with these four sugars do not correlate with their flavor conditioning effects.

Even in the absence of unique flavor cues, postoral sugar sensing can modulate consumatory and appetitive behaviors to obtain sugars. This was demonstrated by the effectiveness of IG sucrose and glucose infusions to reinforce operant licking of an empty sipper tube in B6 mice [81, 82]. In contrast, B6 mice do not maintain operant licking for IG fructose infusions, which is consistent with the failure of IG fructose to condition flavor preferences [81]. More recently, Fernandes et al. [83] reported that oral sucrose and IG sucrose both reinforced operant lever pressing in B6 mice. A critical role for brain dopamine circuits in mediating lever pressing for IG sucrose infusions was revealed by the findings that (a) IG sucrose infusions activated dopamine neurons in the VTA and (b) KO mice with impaired VTA DA neuron function were deficient in their lever pressing for sucrose rewards. The involvement of the hepatic branch of the left vagus nerve in postoral sucrose stimulation of VTA DA neurons and lever press performance was indicated by the results of two experiments. First, selective surgical transection of the common hepatic branch blocked IG sucrose activation of VTA DA neurons. Second, common hepatic branch vagotomy attenuated lever pressing for IG sucrose infusions, although the lack of a complete blockade of lever pressing for IG sucrose implicates other vagal or non-vagal pathways in this response. Nevertheless, the authors implied that the results are consistent with the finding of normal sugarconditioned flavor preferences in animals with SDV sparing the common hepatic branch [99]. However, IG carbohydrate conditioning was observed in animals with surgical SDV that included the common hepatic branch as well as in animals with selective common hepatic branch vagotomy [97-99, 102]. A potential role of dorsal root afferents innervating the hepatic-portal vein and projecting via the celiac/superior mesenteric ganglia and splanchnic nerve to the spinal cord in mediating the effects of absorbed glucose on the hypothalamus is indicated by the findings of Goldstein et al [103], but it is not clear whether this pathway is involved in the learning process.

To summarize, advances in selective neural manipulation and recording have significantly contributed to progress in understanding the nature of the unconditioned sugar signal generated in the gut and the potential pathways linking this signal to reward and reinforcement behavior in the brain. One common finding relates to the importance of intestinal SGLT1 sensing to glucoseconditioned preferences. Recent studies indicate that hepaticportal glucose also contributes to preference learning, although how the sugar is sensed and signaled to the brain is not certain. Also unknown is the mechanism by which postoral fructose conditions flavor preferences in some inbred mice (e.g., FVB/N) [88].

\section{MECHANISMS FOR FAT-CONDITIONED PREFERENCES}

As in the case of carbohydrates, many studies demonstrated that orally consumed or postorally infused fat emulsions condition flavor preferences, including that of fat, in rats and mice $[27,85]$. Flavor preferences vary as a function of fat source, with long-chain triglycerides being more effective than medium-chain triglycerides, and some triglyceride fat sources more effective than others (e.g., corn oil and safflower oil vs. beef tallow and vegetable shortening) [104]. In rats, postoral fat infusions condition weaker flavor preferences than do isocaloric sugar infusions [105] and require more training trials [106], but this is not the case in mice [107-109].

In addition to conditioning CS+ flavor preferences, IG fat infusions rapidly stimulate $\mathrm{CS}+$ intakes in the first training sessions in mice, which suggests a preabsorptive site of action $[107,109]$. In order to be effective, infused fat must be digested to fatty acids which can act on multiple intestinal fatty acid sensors including CD36, GPR120 [O3FAR1], and GPR40 [FFAR1] [110] (Fig. 2). CD36 KO mice did not differ from WT mice in their preference conditioning response to IG soybean oil infusions [111]. In contrast, GPR40/120 double knockout (DKO) mice showed only a marginal fat-conditioned flavor preference with 1-h training sessions relative to WT mice (58\% vs. $81 \%$ ) [112]. However, with 24-h training, GPR40/120 DKO mice displayed a more substantial conditioned preference although still weaker than that of WT mice (70\% vs. $96 \%)$. The $24-\mathrm{h}$ results indicate that other intestinal or postabsorptive sensors contribute to long-term fat-conditioned preferences, e.g., GPR41, GPR43, GPR119 [34].

The gut-brain pathways that mediate postoral fat conditioning are not fully understood. Early studies indicated that vagal afferents are not essential because surgical or capsaicin vagal deafferentation did not prevent animals from learning to prefer a CS+ flavor paired with postoral fat infusions [98, 113]. However, Qu et al. [97] reported that, unlike control mice, SDV mice did not learn to prefer an orally consumed $7.5 \%$ fat emulsion over a $30 \%$ emulsion, which was taken as evidence for "a deficit in lipid postoral signaling." Why control mice preferred the less concentrated emulsion was not explained but it may have occurred because the satiating actions of the $30 \%$ fat counteracted its postoral appetition actions [114]. Conceivably, the SDV mice did 
2164

not come to prefer the $7.5 \%$ fat because vagotomy reduced the satiating and therefore the appetition-limiting actions of the $30 \%$ fat. In another study by the same investigators [84], bilateral afferent vagotomies were produced by targeting nodose neurons using the neurotoxin caspase (Caspase vagotomy) or CCK receptor-expressing vagal neurons using the neurotoxin saporin (CCK-SAP vagotomy). Flavor conditioning was evaluated by training mice (1-h/day) with a CS+ flavor paired with IG infusions of $5 \%$ lipid and a different CS+ flavor paired with IG infusions of $20 \%$ lipid (which were diluted in the gut to $2.5 \%$ and $10 \%$ lipid, respectively by the consumed CS solutions). With this procedure, the control mice learned to prefer the CS $+20 \%$ flavor to the CS+ $5 \%$ flavor while the sensory vagotomized mice equally preferred the two CS+ flavors. This finding, however, does not demonstrate that the vagotomized mice were completely insensitive to postoral fat reinforcement because their preference for a waterpaired CS - flavor was not evaluated [115]. Also, the control and vagotomized groups displayed similar increases in CS+ $5 \%$ and CS $+20 \%$ intakes during one-bottle training sessions which is indicative of postoral fat reinforcement [116]. On the other hand, in operant licking tests reinforced with IG infusions of $20 \%$ fat, Caspase and CCK-SAP vagotomized mice, unlike controls, did not increase their licking responses over test sessions which indicates a reduced sensitivity to postoral fat reinforcement [84].

In addition to investigating postoral fat reward, Han et al. [84] reported on the reward effects of optogenetic activation of vagal afferent neurons projecting to the upper gut, using a combination of a Cre-expressing adeno-associated virus injected into the stomach and duodenum retrogradely transported to the nodose ganglia, and a Cre-dependent light-sensitive depolarizing channel injected into the left or right nodose ganglia. Using this approach, they demonstrated that optogenetic activation of gut-projecting afferent neurons in the right nodose ganglion (NG) had rewarding actions as indicated by reinforcing (a) nose poking behavior; (b) place preference conditioning; (c) flavor preference conditioning; and by stimulating (d) dorsal striatal dopamine release. In contrast, activation of neurons in the left NG had none of these effects. The optogenetic findings imply that the right nodose mediates fatconditioned preferences, although Han et al. [84] did not evaluate the effects of unilateral vagal afferent silencing on fat conditioning. The failure of left NG activation to have reinforcing effects implies that vagal afferents mediating sugar reward do not pass through the left NG, but Tan et al. [65] reported that intestinal glucose equally activates vagal neurons in the left and right NG. Further research is needed to resolve the vagal pathways involved in fat and sugar reward.

The finding that selective deactivation of CCK-responsive vagal afferents blocks flavor conditioning suggests a possible role of nutrient-stimulated CCK release in such conditioning. An early study reported that pairing a CS + flavor with systemic injection of a low dose of exogenous CCK conditioned a mild flavor preference while higher doses were ineffective or conditioned a flavor avoidance [117]. Yet, blocking CCK receptors with devazepide did not prevent IG nutrient-conditioned preferences, indicating that CCK signaling is not essential for postoral nutrient conditioning [118]. Ghrelin is another gut hormone implicated in food reward processing, but experiments with ghrelin receptor $\mathrm{KO}$ mice and ghrelin receptor antagonists indicate that ghrelin signaling is not essential for flavor preferences conditioning by IG sugar or fat infusions [77].

In summary, contrary to earlier surgical vagotomy results, recent findings implicate vagal afferents perhaps limited to the right nodose ganglion in flavor conditioning by dilute vs. concentrated fat emulsions and in operant licking for IG fat infusions [84]. Additional work is needed to verify the exclusive involvement of vagal afferents on the right side in $\mathrm{CS}+$ high vs. CS+ low fat conditioning as well as fat-conditioned $\mathrm{CS}+$ preferences relative to a water-paired CS-.

\section{MECHANISMS FOR PROTEIN-CONDITIONED PREFERENCES}

Orally consumed or postorally administered dietary proteins condition flavor preferences in animals [27, 85]. Relatively little is known, however, about the postoral mechanisms mediating this form of nutrient learning. In rats protein-conditioned flavor preferences are differentially altered by postoral carbohydrate and protein loads, indicating that the animals distinguish between postoral signals generated by these nutrients [119]. Given the diversity of proteins, it is likely that postoral signaling is mediated by one or more common amino acids. Glutamate is one such amino acid and is the prototype for the umami taste receptor (T1R1+T1R3) found in oral taste buds and intestinal enteroendocrine cells [120]. IG infusion of monosodium glutamate (MSG) conditions CS + flavor preferences in rats and mice [121-123]. Total subdiaphragmatic vagotomy (SDV) and SDV with spared hepatic branch blocked flavor conditioning by IG MSG infusions whereas selective common hepatic branch vagotomy was ineffective [100]. SDV also greatly reduced the activation of brain areas by IG MSG infusions [100]. These findings implicate vagal afferents outside the common hepatic branch in postoral glutamate reinforcement, although this requires confirmation with more selective vagal deafferentation procedures. The postoral glutamate sensor that mediated MSG conditioning is not known but does not require the T1R3 receptor. This is indicated by the finding that T1R3 KO mice, like WT mice, develop preferences for MSG and a MSG-paired CS+ flavor after one-bottle training [124]. The role of other gut glutamate sensors (mGlu1, mGlu4, CaSR) in MSG conditioning remains to be investigated [120].

Thus, there is now evidence implicating vagal afferents in the appetite (preference and acceptance) conditioning actions of sugar, fat, and glutamate in the gut. Interestingly, other recent findings implicate vagal afferents in the hunger state induced by fasting $[125,126]$. In one study, selective ghrelin receptor (GHSR) knockdown in vagal afferent neurons abrogated the hyperphagic effect of ghrelin administered at dark onset and caused other behavioral and metabolic impairments [126]. Another study identified a subpopulation of fasting-activated NTS neurons co-expressing epinephrine and NPY, the optogenetic activation of which stimulated feeding and generated conditioned place preference [125]. This is in marked contrast to the conditioned place preference produced by activation of vagal afferents linked to postoral fat reward [84]. Taken together, these findings indicate that distinct vagal-NTS pathways mediate the appetite/reward actions of nutrients in the gut and the hunger/ aversive actions of fasting.

\section{IMPLICATIONS FOR FOOD CHOICE BEHAVIOR AND TREATMENT OR PREVENTION OF OBESITY}

From the above discussions, it is clear that rodents use signals generated by the interaction of specific nutrients with upper intestinal enteroendocrine/neuropod cells and vagal sensory neurons to learn preferences and make choices. There seem to be separate signals for acceleration (appetition, reward) and deceleration (satiation) of intake, and the combined effects are important determinants of total energy intake at least in the short term. However, because in most studies, relatively simple binary choices such as glucose vs. water, or low vs. high concentrations of fat emulsions were used [but see [127]], translation to real world situations with much more complex food choices is difficult. As discussed elsewhere, nutrient-conditioned preferences are documented in humans, but such conditioning is less readily obtained in humans, particularly adults, than in rodents [27, 128, 129]. Future studies need to address these species differences. We also have not yet seen any study that examines macronutrient choice behavior in rodents with specific pathway deletions. For example, would permanent silencing of the neuropod signal which renders mice unable to recognize glucose [68] change their long-term macronutrient choice using the geometric model? 
Another unanswered question is whether the changes in energy intake resulting from specific pathway deletions have any long-lasting effects on energy regulation and the development of obesity, as quantitative or qualitative changes in food intake do not necessarily lead to changes in body weight. For example, would silencing glucose-sensitive NTS neurons which suppress 24-h sugar intake [65] lead to long-term reductions in the intake of sugar-rich drinks or foods and thereby attenuate sugar-induced obesity? Tools are now available to carry out inducible deletions of specific populations of vagal afferent neurons. Given that at least some pathways include vagal afferent signaling, could it be that the numbing of vagal afferent function observed in high-fat fed mice [130] includes these critical vagal afferent populations, and what implications might this have on the course of obesity?

Bariatric surgeries are currently the most effective treatment option for obesity, and there is great interest in deciphering the mechanisms for their success. A role for vagal afferents contained within the celiac branches in the weight loss effects of Roux-en-Y gastric bypass surgery has been demonstrated in rats [131], but it is not known whether the surgical celiac branch vagotomy affected the vagal afferents mediating the neuropod signal described by Buchanan et al. [68] or the vagal afferent neurons described by Tan et al. [65]. In another study in rats, the common hepatic branch of the left vagus, which was implicated in the detection of the sugar signal by Fernandes et al. [83], was not required for the weight-lowering effects of RYGB [132]. It was claimed that a gut-vagal afferent-striatal pathway is recruited by RYGB to reduce fat appetite in obese rats [133]. However, when this pathway was interrupted with total subdiaphragmatic truncal vagotomy (SDV), RYGB reduced body weight to exactly the same extent as in sham vagotomized rats [133]. Again, the discrepancy in these outcomes could be due to the issues with non-selectivity of SDV and common hepatic branch vagotomy that were described above.

As to potential relevance of sugar-conditioned preferences for treating or preventing obesity, it may be feasible to mimic the absorption of sugar by activating the downstream signaling pathways. Tan and colleagues have already provided proof of principle for such an approach by injecting a Cre-dependent AAV encoding an excitatory designer receptor into the proenkephalinexpressing neurons in the cNTS that are critical for preferences based on sugar sensing [65]. Activating the designer receptor led to a complete switch in licking from a preferred sweet grapeflavored solution to a previously much less preferred non-sweet cherry-flavored solution [65]. It would be interesting to test whether other components of the gut-to-brain sugar-signaling pathway, such as the specific vagal afferent neuron population, or the molecular pathways coupling the SGLT1 transporter to vagal afferents could also be co-opted. Once the specific signaling pathways for fat and protein preference have been identified they could be similarly co-opted for healthier eating.

\section{CONCLUSIONS AND FUTURE DIRECTIONS}

The wide availability of foods rich in sugar and fat is a significant factor in the current obesity epidemic. The inherently attractive flavor of these foods is one factor that promotes their selection and consumption. Rodent studies have established that sugar and fat also activate nutrient sensors in the gut that signal brain reward and learning systems that further enhance the wanting and liking of foods high in these nutrients. Until recently, little was known about the gut-brain pathways that transmit nutrientgenerated appetition signals. Recent studies now implicate vagal afferent connections between intestinal nutrient sensing enteroendocrine and neuropod cells and caudal NTS neurons which project to higher brain systems. In the case of sugars, glucose binds to the SGLT1 transporter/sensor on neuropod cells which, in turn, activates glutamatergic synaptic receptors on adjacent vagal afferent fibers. Postabsorptive glucose is also detected at hepaticportal sites although the sensing mechanism and signaling pathway to the brain are uncertain. In the case of fats, fatty acids act in part on GPR40 and GPR120 intestinal receptors which, in turn, stimulate CCK-sensitive afferent fibers. Other pre- and/or postabsorptive fatty acid sensors are also implicated in postoral fat appetition. Central neural systems triggered by these visceral appetition signals include striatal dopamine circuits and limbic motivational and hippocampal memory circuits [134, 135]. Many details remain to be elucidated, including the relative ineffectiveness of some sugars (fructose, galactose) to stimulate appetite, failure of surgical vagotomy to block flavor conditioning, and the contribution of visceral appetition signals to long-term food intake and body weight regulation. Most importantly, the role of the newly revealed gut nutrient sensors and gut-brain pathways in human food appetite and preferences, and how these gut appetition mechanisms might contribute to therapeutic approaches to overeating and obesity, need further exploration.

\section{REFERENCES}

1. Collaboration NCDRF. Worldwide trends in body-mass index, underweight, overweight, and obesity from 1975 to 2016: a pooled analysis of 2416 population-based measurement studies in 128.9 million children, adolescents, and adults. Lancet. 2017;390:2627-42.

2. Malik VS, Willet WC, Hu FB. Nearly a decade on - trends, risk factors and policy implications in global obesity. Nat Rev Endocrinol. 2020;16:615-6.

3. Allender S, Owen B, Kuhlberg J, Lowe J, Nagorcka-Smith P, Whelan J, et al. A community based systems diagram of obesity causes. PLoS One. 2015;10: e0129683.

4. Berthoud HR, Morrison CD, Munzberg $H$. The obesity epidemic in the face of homeostatic body weight regulation: What went wrong and how can it be fixed? Physiol Behav 2020;222:112959.

5. Boyland EJ, Whalen R. Food advertising to children and its effects on diet: review of recent prevalence and impact data. Pediatr Diabetes. 2015;16:331-7.

6. Sadeghirad B, Duhaney T, Motaghipisheh S, Campbell NR, Johnston BC. Influence of unhealthy food and beverage marketing on children's dietary intake and preference: a systematic review and meta-analysis of randomized trials. Obes Rev 2016;17:945-59.

7. Cannon W. The wisdom of the body, Norton: New York, 1939.

8. Richter C. Total self-regulatory functions of animals and human beings. Harvey Lect. 1943;38:63-103.

9. Galef BG Jr. A contrarian view of the wisdom of the body as it relates to dietary self-selection. Psychol Rev 1991;98:218-23.

10. Berthoud HR, Seeley RJ. Neural and Metabolic Control of Macronutrient Intake, CRC Press: Boca Raton, 2000.

11. Seeley RJ, Berthoud HR Neural and metabolic control of macronutrient selection: consensus and controversy. In: Berthoud HR, Seeley RJ, eitors. Neural and metabolic control of macronutrient intake. CRC Press: Boca Raton, 2000, pp 489-96.

12. Wiater MF, Hudson BD, Virgin $Y$, Ritter $S$. Protein appetite is increased after central leptin-induced fat depletion. Am J Physiol Regul Integr Comp Physiol. 2007;293:R1468-73.

13. Raubenheimer $D$, Simpson SJ. Protein leverage: theoretical foundations and ten points of clarification. Obesity (Silver Spring). 2019;27:1225-38.

14. Hill CM, Qualls-Creekmore E, Berthoud HR, Soto P, Yu S, McDougal DH, et al. FGF21 and the Physiological regulation of macronutrient preference. Endocrinology. 2020;161:3.

15. Hao S, Sharp JW, Ross-Inta CM, McDaniel BJ, Anthony TG, Wek RC, et al. Uncharged tRNA and sensing of amino acid deficiency in mammalian piriform cortex. Science. 2005;307:1776-8.

16. Fromentin G, Darcel N, Chaumontet C, Marsset-Baglieri A, Nadkarni N, Tome D. Peripheral and central mechanisms involved in the control of food intake by dietary amino acids and proteins. Nutr Res Rev 2012;25:29-39.

17. Berthoud HR. The neurobiology of food intake in an obesogenic environment. Proc Nutr Soc. 2012;71:478-87.

18. Hu FB. Resolved: there is sufficient scientific evidence that decreasing sugarsweetened beverage consumption will reduce the prevalence of obesity and obesity-related diseases. Obes Rev 2013;14:606-19.

19. Bray GA, Popkin BM. Dietary sugar and body weight: have we reached a crisis in the epidemic of obesity and diabetes?: health be damned! Pour on the sugar. Diabetes Care. 2014;37:950-6. 
20. Simpson SJ, Batley R, Raubenheimer D. Geometric analysis of macronutrient intake in humans: the power of protein? Appetite. 2003;41:123-40.

21. Larsson MH, Hakansson P, Jansen FP, Magnell K, Brodin P. Ablation of TRPM5 in mice results in reduced body weight gain and improved glucose tolerance and protects from excessive consumption of sweet palatable food when fed high caloric diets. PLoS One. 2015;10:e0138373.

22. Andres-Hernando A, Kuwabara M, Orlicky DJ, Vandenbeuch A, Cicerchi C, Kinnamon SC, et al. Sugar causes obesity and metabolic syndrome in mice independently of sweet taste. Am J Physiol Endocrinol Metab 2020;319:E276-E290.

23. Glendinning Jl, Gillman J, Zamer H, Margolskee RF, Sclafani A. The role of T1r3 and Trpm5 in carbohydrate-induced obesity in mice. Physiol Behav 2012;107:50-8.

24. Linne $Y$, Barkeling B, Rossner S, Rooth P. Vision and eating behavior. Obes Res 2002;10:92-5.

25. Gibbs J, Smith GP. Cholecystokinin and satiety in rats and rhesus monkeys. Am J Clin Nutr 1977;30:758-61.

26. Sclafani A. How food preferences are learned: laboratory animal models. Proc Nutr Soc 1995;54:419-27.

27. Sclafani A, Ackroff K. Formation of flavor aversions and preferences. In: Myerhof BFW (ed) The senses: a comprehensive reference, Second Edition. Elsevier: Oxford, 2020, pp 333-52.

28. Berthoud HR, Neuhuber WL. Functional and chemical anatomy of the afferent vagal system. Auton Neurosci 2000;85:1-17.

29. Bai L, Mesgarzadeh S, Ramesh KS, Huey EL, Liu Y, Gray LA, et al. Genetic identification of vagal sensory neurons that control feeding. Cell. 2019;179:1129-43. e23

30. Worthington JJ, Reimann F, Gribble FM. Enteroendocrine cells-sensory sentinels of the intestinal environment and orchestrators of mucosal immunity. Mucosal Immunol. 2018;11:3-20.

31. Gribble FM, Reimann F. Enteroendocrine cells: chemosensors in the intestinal epithelium. Annu Rev Physiol 2016;78:277-99.

32. Koepsell $H$. Glucose transporters in the small intestine in health and disease. Pflugers Arch. 2020;472:1207-48.

33. Gorboulev V, Schürmann A, Vallon V, Kipp H, Jaschke A, Klessen D, et al. Na (+)-D-glucose cotransporter SGLT1 is pivotal for intestinal glucose absorption and glucose-dependent incretin secretion. Diabetes. 2012;61:187-96.

34. Raka F, Farr S, Kelly J, Stoianov A, Adeli K. Metabolic control via nutrient-sensing mechanisms: role of taste receptors and the gut-brain neuroendocrine axis. Am J Physiol Endocrinol Metab 2019;317:E559-E572.

35. Daniel H. Molecular and integrative physiology of intestinal peptide transport. Annu Rev Physiol 2004;66:361-84.

36. Ko CW, Qu J, Black DD, Tso P. Regulation of intestinal lipid metabolism: current concepts and relevance to disease. Nat Rev Gastroenterol Hepatol 2020;17:169-83.

37. Gribble FM, Reimann F. Function and mechanisms of enteroendocrine cells and gut hormones in metabolism. Nat Rev Endocrinol 2019;15:226-37.

38. Psichas A, Reimann F, Gribble FM. Gut chemosensing mechanisms. J Clin Invest 2015;125:908-17.

39. Grundy D. Neuroanatomy of visceral nociception: vagal and splanchnic afferent. Gut. 2002;51:i2-5.

40. Janig W. The integrative action of the autonomic nervous system, Cambridge University Press: Cambridge, 2006

41. Sugiura $Y$, Terui N, Hosoya $Y$, Tonosaki $Y$, Nishiyama K, Honda T. Quantitative analysis of central terminal projections of visceral and somatic unmyelinated (C) primary afferent fibers in the guinea pig. J Comp Neurol 1993;332:315-25.

42. Schwartz GJ, Moran TH. CCK elicits and modulates vagal afferent activity arising from gastric and duodenal sites. Ann NY Acad Sci 1994;713:121-8.

43. Berthoud HR, Patterson LM. Anatomical relationship between vagal afferent fibers and CCK-immunoreactive entero-endocrine cells in the rat small intestinal mucosa. Acta Anat (Basel). 1996;156:123-31.

44. Berthoud HR, Blackshaw LA, Brookes SJ, Grundy D. Neuroanatomy of extrinsic afferents supplying the gastrointestinal tract. Neurogastroenterol Motil 2004;16:28-33.

45. Powley TL, Spaulding RA, Haglof SA. Vagal afferent innervation of the proximal gastrointestinal tract mucosa: chemoreceptor and mechanoreceptor architecture. J Comp Neurol 2011;519:644-60.

46. Mei N. Vagal glucoreceptors in the small intestine of the cat. J Physiol 1978;282:485-506.

47. Mei N. Recent studies on intestinal vagal afferent innervation. Functional implications J Auton Nerv Syst 1983;9:199-206.

48. Mei N. Intestinal chemosensitivity. Physiol Rev 1985;65:211-37.

49. Jeanningros R. Vagal unitary responses to intestinal amino acid infusions in the anesthetized cat: a putative signal for protein induced satiety. Physiol Behav $1982 ; 28: 9-21$
50. Melone J. Vagal receptors sensitive to lipids in the small intestine of the cat. J Auton Nerv Syst 1986;17:231-41.

51. Babic T, Townsend RL, Patterson LM, Sutton GM, Zheng H, Berthoud HR. Phenotype of neurons in the nucleus of the solitary tract that express CCK-induced activation of the ERK signaling pathway. Am J Physiol Regul Integr Comp Physiol 2009;296:R845-54.

52. Glatzle J, Kreis ME, Kawano K, Raybould HE, Zittel TT. Postprandial neuronal activation in the nucleus of the solitary tract is partly mediated by CCK-A receptors. Am J Physiol Regul Integr Comp Physiol 2001;281:R222-9.

53. Burdyga G, de Lartigue G, Raybould HE, Morris R, Dimaline R, Varro A, et al. Cholecystokinin regulates expression of $\mathrm{Y} 2$ receptors in vagal afferent neurons serving the stomach. J Neurosci 2008;28:11583-92.

54. Labouesse MA, Stadlbauer U, Weber E, Arnold M, Langhans W, Pacheco-Lopez G. Vagal afferents mediate early satiation and prevent flavour avoidance learning in response to intraperitoneally infused exendin-4. J Neuroendocrinol 2012;24:1505-16.

55. Ronveaux CC, Tome D, Raybould HE. Glucagon-like peptide 1 interacts with ghrelin and leptin to regulate glucose metabolism and food intake through vagal afferent neuron signaling. J Nutr 2015;145:672-80.

56. Krieger JP, Arnold M, Pettersen KG, Lossel P, Langhans W, Lee SJ. Knockdown of GLP-1 receptors in vagal afferents affects normal food intake and glycemia. Diabetes. 2016;65:34-43.

57. Prechtl JC, Powley TL. A light and electron microscopic examination of the vagal hepatic branch of the rat. Anat Embryol (Berl) 1987;176:115-26.

58. Berthoud HR, Kressel M, Neuhuber WL. An anterograde tracing study of the vagal innervation of rat liver, portal vein and biliary system. Anat Embryol (Berl) 1992;186:431-42.

59. de Lartigue G, Ronveaux CC, Raybould HE. Deletion of leptin signaling in vagal afferent neurons results in hyperphagia and obesity. Mol Metab 2014;3:595-607.

60. Gautron L, Sakata I, Udit S, Zigman JM, Wood JN, Elmquist JK. Genetic tracing of Nav1.8-expressing vagal afferents in the mouse. J Comp Neurol 2011;519:3085-101.

61. Williams EK, Chang RB, Strochlic DE, Umans BD, Lowell BB, Liberles SD. Sensory neurons that detect stretch and nutrients in the digestive system. Cell. 2016;166:209-21.

62. Egerod KL, Petersen N, Timshel PN, Rekling JC, Wang Y, Liu Q, et al. Profiling of G protein-coupled receptors in vagal afferents reveals novel gut-to-brain sensing mechanisms. Mol Metab 2018;12:62-75.

63. Huang KP, Goodson ML, Vang W, Li H, Page AJ, Raybould HE. Leptin signaling in vagal afferent neurons supports the absorption and storage of nutrients from high-fat diet. Int J Obes (Lond). 2020;45:348-57.

64. Kupari J, Haring M, Agirre E, Castelo-Branco G, Ernfors P. An atlas of vagal sensory neurons and their molecular specialization. Cell Rep. 2019;27:2508-23. e4.

65. Tan HE, Sisti AC, Jin $H$, Vignovich $M$, Villavicencio $M$, Tsang $K S$, et al. The gutbrain axis mediates sugar preference. Nature. 2020;580:511-6.

66. Bohórquez DV, Shahid RA, Erdmann A, Kreger AM, Wang Y, Calakos N, et al. Neuroepithelial circuit formed by innervation of sensory enteroendocrine cells. J Clin Invest 2015;125:782-6.

67. Kaelberer MM, Buchanan KL, Klein ME, Barth BB, Montoya MM, Shen X, et al. A gut-brain neural circuit for nutrient sensory transduction. Science. 2018:361:6408.

68. Buchanan $K L$, Rupprecht,LE, Sahasrabudhe,A, Kaelberer,MM, Klein,M, Villalobos, J, et al. A gut sensor for sugar preference. bioRxiv 2020; https://doi.org/10.1101/ 2020.03.06.981365

69. Kaelberer MM, Rupprecht LE, Liu WW, Weng P, Bohorquez DV. Neuropod cells: the emerging biology of gut-brain sensory transduction. Annu Rev Neurosci 2020:43:337-53.

70. Müller TD, Finan B, Bloom SR, D'alessio D, Drucker DJ, Flatt PR, et al. Glucagonlike peptide 1 (GLP-1). Mol Metab 2019;30:72-130.

71. Sclafani A, Ackroff K. Nutrient-conditioned intake stimulation does not require a distinctive flavor cue in rats. Appetite. 2020;154:104793.

72. Chambers KC. Conditioned taste aversions. World J Otorhinolaryngol Head Neck Surg. 2018;4:92-100.

73. Lin JY, Arthurs J, Reilly S. Conditioned taste aversions: From poisons to pain to drugs of abuse. Psychon Bull Rev 2017;24:335-51.

74. Zukerman S, Ackroff $\mathrm{K}$, Sclafani A. Post-oral glucose stimulation of intake and conditioned flavor preference in $\mathrm{C} 57 \mathrm{BL} / 6 \mathrm{~J}$ mice: a concentration-response study. Physiol Behav 2013;109:33-41.

75. Sclafani A. Gut-brain nutrient signaling. Appetition vs satiation. Appetite. 2013;71:454-8

76. Warwick ZS, Weingarten HP. Dissociation of palatability and calorie effects in learned flavor preferences. Physiol Behav 1994;55:501-4.

77. Sclafani A, Touzani K, Ackroff K. Ghrelin signaling is not essential for sugar or fat conditioned flavor preferences in mice. Physiol Behav 2015;149:14-22. 
78. Sclafani A, Zukerman S, Ackroff K. Postoral glucose sensing, not caloric content, determines sugar reward in C57BL/6J mice. Chem Senses. 2015;40:245-58.

79. White NM, Carr GD. The conditioned place preference is affected by two independent reinforcement processes. Pharmacol Biochem Behav 1985;23:37-42.

80. de Araujo IE, Oliveira-Maia AJ, Sotnikova TD, Gainetdinov RR, Caron MG, Nicolelis $M A$, et al. Food reward in the absence of taste receptor signaling. Neuron. 2008;57:930-41.

81. Sclafani A, Ackroff K. Operant licking for intragastric sugar infusions: Differential reinforcing actions of glucose, sucrose and fructose in mice. Physiol Behav 2016;153:115-24.

82. Ferreira JG, Tellez LA, Ren X, Yeckel CW, de Araujo IE. Regulation of fat intake in the absence of flavour signalling. J Physiol. 2012;590:953-72.

83. Fernandes AB, Alves da Silva J, Almeida J, Cui G, Gerfen CR, Costa RM, et al. Postingestive modulation of food seeking depends on vagus-mediated dopamine neuron activity. Neuron. 2020;106:778-88. e6.

84. Han W, Tellez LA, Perkins MH, Perez IO, Qu T, Ferreira J, et al. A neural circuit for gut-induced reward. Cell. 2018;175:665-78. e23.

85. Sclafani A, Ackroff K. Role of gut nutrient sensing in stimulating appetite and conditioning food preferences. Am J Physiol Regul Integr Comp Physiol 2012;302:R1119-33.

86. Sclafani A, Cardieri C, Tucker K, Blusk D, Ackroff K. Intragastric glucose but not fructose conditions robust flavor preferences in rats. Am J Physiol 1993;265: R320-5.

87. Sclafani A, Ackroff K. Flavor preferences conditioned by intragastric glucose but not fructose or galactose in C57BL/6J mice. Physiol Behav 2012;106:457-61.

88. Sclafani A, Zukerman S, Ackroff K. Fructose- and glucose-conditioned preferences in FVB mice: strain differences in post-oral sugar appetition. Am J Physiol Regul Integr. Comp Physiol 2014;307:R1448-57.

89. Drucker DB, Sclafani A. The role of gastric and postgastric sites in glucoseconditioned flavor preferences in rats. Physiol Behav 1997;61:351-8.

90. Ackroff K, Yiin YM, Sclafani A. Post-oral infusion sites that support glucoseconditioned flavor preferences in rats. Physiol Behav 2010;99:402-11.

91. Tordoff MG, Friedman MI. Hepatic portal glucose infusions decrease food intake and increase food preference. Am J Physiol 1986;251:R192-6.

92. Oliveira-Maia AJ, Roberts CD, Walker QD, Luo B, Kuhn C, Simon SA, et al. Intravascular food reward. PLoS One. 2011;6:e24992.

93. Sclafani A, Glass DS, Margolskee RF, Glendinning Jl. Gut T1R3 sweet taste receptors do not mediate sucrose-conditioned flavor preferences in mice. Am J Physiol Regul Integr Comp Physiol 2010;299:R1643-50.

94. Zukerman S, Ackroff K, Sclafani A. Post-oral appetite stimulation by sugars and nonmetabolizable sugar analogs. Am J Physiol Regul Integr Comp Physiol 2013;305:R840-53.

95. Sclafani A, Koepsell H, Ackroff K. SGLT1 sugar transporter/sensor is required for post-oral glucose appetition. Am J Physiol Regul Integr Comp Physiol 2016;310: R631-9.

96. Zhang L, Han W, Lin C, Li F, de Araujo IE. Sugar metabolism regulates flavor preferences and portal glucose sensing. Front Integr Neurosci 2018;12:57.

97. Qu T, Han W, Niu J, Tong J, de Araujo IE. On the roles of the duodenum and the vagus nerve in learned nutrient preferences. Appetite. 2019;139:145-51.

98. Sclafani A, Ackroff K, Schwartz GJ. Selective effects of vagal deafferentation and celiac-superior mesenteric ganglionectomy on the reinforcing and satiating action of intestinal nutrients. Physiol. Behav. 2003;78:285-94.

99. Sclafani A, Lucas F. Abdominal vagotomy does not block carbohydrateconditioned flavor preferences in rats. Physiol Behav 1996;60:447-53.

100. Uematsu A, Tsurugizawa T, Uneyama H, Torii K. Brain-gut communication via vagus nerve modulates conditioned flavor preference. Eur J Neurosci 2010;31:1136-43.

101. Maniscalco JW, Rinaman L. Vagal interoceptive modulation of motivated behavior. Physiology (Bethesda). 2018;33:151-67.

102. Horn CC, Mitchell JC. Does selective vagotomy affect conditioned flavor-nutrient preferences in rats? Physiol Behav 1996;59:33-8.

103. Goldstein N, McKnight AD, Carty JR, Arnold M, Betley JN, Alhadeff AL. Hypothalamic detection of macronutrients via multiple gut-brain pathways. Cell Metab. 2021;33:676-87.

104. Ackroff K, Lucas F, Sclafani A. Flavor preference conditioning as a function of fat source. Physiol Behav 2005;85:448-60.

105. Lucas F, Sclafani A. Differential reinforcing and satiating effects of intragastric fat and carbohydrate infusions in rats. Physiol Behav 1999;66:381-8.

106. Ackroff K, Dym C, Yiin YM, Sclafani A. Rapid acquisition of conditioned flavor preferences in rats. Physiol Behav 2009;97:406-13.

107. Ackroff K, Sclafani A. Post-oral fat stimulation of intake and conditioned flavor preference in C57BL/6J mice: a concentration-response study. Physiol Behav 2014;129:64-72.
108. Sclafani A, Glendinning Jl. Sugar and fat conditioned flavor preferences in C57BL/6J and 129 mice: oral and postoral interactions. Am J Physiol Regul Integr Comp Physiol 2005;289:R712-20.

109. Zukerman S, Ackroff K, Sclafani A. Rapid post-oral stimulation of intake and flavor conditioning by glucose and fat in the mouse. Am J Physiol Regul Integr Comp Physiol 2011;301:R1635-47.

110. Sclafani A, Ackroff K. Role of lipolysis in postoral and oral fat preferences in mice. Am J Physiol Regul Integr Comp Physiol 2018;315:R434-R441.

111. Sclafani A, Ackroff K, Abumrad NA. CD36 gene deletion reduces fat preference and intake but not post-oral fat conditioning in mice. Am J Physiol Regul Integr Comp Physiol. 2007;293:R1823-32.

112. Sclafani A, Zukerman S, Ackroff K. GPR40 and GPR120 fatty acid sensors are critical for postoral but not oral mediation of fat preferences in the mouse. Am J Physiol. Regul Integr Comp Physiol. 2013;305:R1490-7.

113. Lucas F, Sclafani A. Capsaicin attenuates feeding suppression but not reinforcement by intestinal nutrients. Am J Physiol 1996;270:R1059-64.

114. Sclafani A, Ackroff $\mathrm{K}$. The relationship between food reward and satiation revisited. Physiol Behav 2004;82:89-95.

115. Sclafani A, Ackroff K. Capsaicin-induced visceral deafferentation does not attenuate flavor conditioning by intragastric fat infusions in mice. Physiol Behav 2019;208:112586.

116. Ackroff $\mathrm{K}$, Sclafani A. Post-oral fat stimulation of intake and conditioned flavor preference in C57BL/6J mice: a concentration-response study. Physiol Behav 2014;129:64-72.

117. Perez C, Sclafani A. Cholecystokinin conditions flavor preferences in rats. Am J Physiol 1991;260:R179-85.

118. Perez C, Lucas F. Sclafani A. Devazepide, a CCK(A) antagonist, attenuates the satiating but not the preference conditioning effects of intestinal carbohydrate infusions in rats. Pharmacol Biochem Behav 1998;59:451-7.

119. Perez C, Ackroff K, Sclafani A. Carbohydrate- and protein-conditioned flavor preferences: effects of nutrient preloads. Physiol Behav 1996;59:467-74.

120. Bezencon C, le Coutre J, Damak S. Taste-signaling proteins are coexpressed in solitary intestinal epithelial cells. Chem Senses. 2007;32:41-9.

121. Uematsu A, Tsurugizawa T, Kondoh T, Torii K. Conditioned flavor preference learning by intragastric administration of L-glutamate in rats. Neurosci Lett 2009;451:190-3.

122. Ackroff $\mathrm{K}$, Sclafani A. Flavor preferences conditioned by post-oral infusion of monosodium glutamate in rats. Physiol Behav 2011;104:488-94.

123. Ackroff K, Sclafani A. Flavor preferences conditioned by intragastric monosodium glutamate in mice. Chem Senses. 2013;38:759-67.

124. Ackroff K, Sclafani A. Flavor preferences conditioned by oral monosodium glutamate in mice. Chem Senses. 2013;38:745-58.

125. Chen J, Cheng $M$, Wang $L$, Zhang $L, X u$ D, Cao $P$, et al. A vagal-NTS neural pathway that stimulates feeding. Curr Biol 2020;30:3986-98. e5.

126. Davis EA, Wald HS, Suarez AN, Zubcevic J, Liu CM, Cortella AM, et al. Ghrelin signaling affects feeding behavior, metabolism, and memory through the vagus nerve. Curr. Biol. 2020;30:4510-8. e6.

127. Lucas F, Ackroff K, Sclafani A. High-fat diet preference and overeating mediated by postingestive factors in rats. Am J Physiol 1998;275:R1511-22.

128. Yeomans MR. Flavour-nutrient learning in humans: an elusive phenomenon? Physiol Behav 2012;106:345-55.

129. Myers KP. The convergence of psychology and neurobiology in flavor-nutrient learning. Appetite. 2018;122:36-43.

130. Page AJ, Kentish SJ. Plasticity of gastrointestinal vagal afferent satiety signals. Neurogastroenterol Motil 2017;29:5.

131. Hao Z, Townsend RL, Mumphrey MB, Patterson LM, Ye J, Berthoud HR. Vagal innervation of intestine contributes to weight loss After Roux-en-Y gastric bypass surgery in rats. Obes. Surg. 2014;24:2145-51.

132. Shin AC, Zheng $H$, Berthoud HR. Vagal innervation of the hepatic portal vein and liver is not necessary for Roux-en-Y gastric bypass surgery-induced hypophagia, weight loss, and hypermetabolism. Ann. Surg. 2012;255:294-301.

133. Hankir MK, Seyfried F, Hintschich CA, Diep TA, Kleberg K, Kranz M, et al. Gastric bypass surgery recruits a gut PPAR-alpha-striatal D1R pathway to reduce fat appetite in obese rats. Cell Metab. 2017;25:335-44.

134. Yang AK, Mendoza JA, Lafferty CK, Lacroix F, Britt JP. Hippocampal Input to the nucleus accumbens shell enhances food palatability. Biol. Psychiatry. 2020;87:597-608.

135. de Araujo IE, Schatzker M, Small DM. Rethinking food reward. Annu. Rev. Psychol. 2020;71:139-64.

136. Baader-Pagler T, Eckhardt M, Himmelsbach F, Sauer A, Stierstorfer BE, Hamilton BS. SGLT6 - A pharmacological target for the treatment of obesity? Adipocyte. 2018;7:277-84.

137. Betley JN, Xu S, Cao ZFH, Gong R, Magnus CJ, Yu Y, et al. Neurons for hunger and thirst transmit a negative-valence teaching signal. Nature. 2015;521:180-5. 


\section{ACKNOWLEDGEMENTS}

Research in the HRB laboratory was funded by National Institutes of Health Grant DK047348, and research in the Morrison Laboratory was funded by National Institutes of Health Grant DK105032. Research in the AS and KA laboratory was funded by National Institutes of Health Grant DK031135 and the Research Foundation of the City University of New York. We thank Dr. Diego Bohórquez for providing helpful feedback on the manuscript.

\section{CONFLICT OF INTEREST}

HRB, CDM, KA, and AS have received grant support from the National Institutes of Health.

\section{ADDITIONAL INFORMATION}

Correspondence and requests for materials should be addressed to H.-R.B. or A.S.

Publisher's note Springer Nature remains neutral with regard to jurisdictional claims in published maps and institutional affiliations.

Reprints and permission information is available at http://www.nature.com/ reprints 